Original article (short paper)

\title{
Braking and propulsive impulses in individuals with patellofemoral pain syndrome when walking up and down stairs
}

\author{
Marcelo Camargo Saad \\ Renato Moraes \\ University of São Paulo, Ribeirão Preto, Brazil \\ Lilian Ramiro Felicio \\ Federal University of Uberlândia, Brazil \\ Débora Bevilaqua-Grossi \\ University of São Paulo, Ribeirão Preto, Brazil
}

\begin{abstract}
Patellofemoral pain syndrome (PFPS) is a prevalent clinical condition and it affects gait behavior. Braking and propulsive impulses are important biomechanical parameters obtained from ground reaction forces (GRF), which combine the amount of force applied over a period of time. The aim of this study was to evaluate these impulses while walking up and down stairs in healthy controls and PFPS individuals. The results did not reveal significant differences in braking and propulsive impulses between groups during these activities. Thus, the painful condition on a simple functional activity was insufficient to change the motor strategy to walking up or down the stairs.
\end{abstract}

Keywords: patellofemoral pain syndrome, impulse, ground reaction force.

Resumo - “Análise dos impulsos de frenagem e de propulsão em indivíduos com síndrome da dor femoropatelar durante subida e descida de degraus." A síndrome da dor femoropatelar (SDFP) é uma condição clínica prevalente e que afeta o comportamento da marcha. Impulsos de frenagem e propulsão são importantes parâmetros biomecânicos obtidos a partir da força de reação do solo que combinam a quantidade de força aplicada sobre um período de tempo. O objetivo deste estudo foi avaliar esses impulsos durante a subida e descida de degraus em indivíduos controle saudáveis e com SDFP. Os resultados não revelaram diferenças significativas nos impulsos de frenagem e propulsão entre os grupos durante essas atividades. Assim, a condição dolorosa em uma atividade funcional simples foi insuficiente para modificar a estratégia motora de descer ou subir degraus.

Palavras-chave: síndrome da dor femoropatelar, impulso, força de reação do solo.

Resumen - "Análisis de los impulsos de frenado y propulsión en la personas con síndrome de dolor patelofemoral durante la actividad de subir y bajar un escalón." El Síndrome de dolor patelofemoral (SDPF) es una condición médica prevalente que afecta al comportamiento de la marcha. Impulso de propulsión y de frenado son parámetros biomecánicos importantes obtenidos a partir de la fuerza de reacción del suelo que combinan la cantidad de fuerza aplicada durante un período de tiempo. El objetivo del estudio fue evaluar estos impulsos durante las actividades de subir y bajar un escalón en sujetos sanos y con SDP. Los resultados no mostraron diferencias significativas en los impulsos de frenado y propulsion entre los grupos durante las actividades. Por lo tanto, Por lo tanto, la condición dolorosa en una actividad funcional simple, no fue suficiente para cambiar la estratégia de subir y bajar un escalón.

Palabras clave: síndrome de dolor patelofemoral, impulso, fuerza de reacción del suelo.

\section{Introduction}

Patellofemoral pain syndrome (PFPS) is a prevalent clinical condition (Boling et al., 2010; Da Cunha et al., 2013; Davis \& Powers, 2010). Several researchers investigated different motor tasks such as running, walking, jumping, and walking up and down stairs in patients with PFPS (Magalhães et al., 2010;
Nakagawa, Moriya, Maciel, \& Serrão, 2012). Among these motor tasks, walking up and down stairs are the most painful and challenging activities for individuals with PFPS because they can exacerbate the pain symptoms (Bretcher \& Powers, 2002).

Different parameters such as ground reaction forces (GRF), center of pressure displacement, electromyography activity of muscle groups mainly involved in these tasks, and movement 
analysis of hip, knee and trunk segments are studied to attempt to identify changes in movement control in these individuals (Boling et al., 2009; Nakagawa et al., 2012; Saad, Felício, Masullo, Liporaci, \& Bevilaqua-Grossi, 2011). Overall, these studies showed that PFPS individuals presented lower values of vertical GRF for the affected limb in a jump-landing task (Boling et al., 2009) and when walking up and down stairs (Saad et al., 2011). They also presented reduced levels of EMG activity (Saad et al., 2011) and increased hip adduction, knee abduction, and trunk lean in the frontal plane (Nakagawa et al., 2012) when walking up and down stairs.

Although previous studies showed that PFPS individuals reduced their vertical GRF, a more comprehensive view of the changes in movement control can be achieved by looking at the force applied on the ground over a period of time, that is, the impulse, which measures how the momentum of the body changes (Enoka, 2008). Walking up or down stairs involves changing body momentum appropriately to successfully perform these tasks. Gait studies have split braking impulse from propulsive impulse (Moraes, Allard, \& Patla, 2007; Peterson, Kautz, \& Neptune, 2011). Braking impulse corresponds to the deceleration period of the support phase, whereas the propulsive impulse corresponds to the acceleration phase of the support phase (Moraes et al., 2007). Both braking and propulsive impulses are computed for vertical and horizontal directions. Both vertical and horizontal components of the impulses are regulated to properly control step length and width (Begg, Sparrow, \& Lythgo, 1998; Moraes et al., 2007, Patla, Robinson, Samways, \& Armstrong, 1989; Warren, Young, \& Lee, 1986). For instance, step lengthening is associated with an increase in propulsive impulse in both vertical and anterior-posterior (AP) directions, whereas increase in step width is associated with greater medial-lateral (ML) propulsive impulse.

Mochida et al. (2009) found that individuals with chronic knee pain showed increased GRF braking and propulsive peaks while stepping, indicating knee overload. Similarly, Zeni, and Higginson (2009) also found changes in these parameters in individuals with moderate to severe pain. Saad et al. (2011) assessed only the vertical component of the GRF while walking up and down stairs. They showed a reduction in both active and passive peaks for individuals with PFPS when walking down a staircase. This variable represents essentially the amount of overload applied on to the musculoskeletal system. To fully understand how this task is controlled by individuals with PFPS, a more comprehensive analysis of the GRF is required. Therefore, the present study re-analyzed this previous data set in order to compute braking and propulsive impulses in both AP and vertical directions. Thus, the purpose of this study was to evaluate the braking and propulsive impulses derived from the GRF while healthy individuals and patients with PFPS walked up and down stairs. Based on the data from Saad et al. (2011), we hypothesized that PFPS individuals would reduce braking and propulsive impulses when walking down stairs, but would not change them when walking up stairs.

\section{Methods}

\section{Participants}

Thirty sedentary female volunteers participated in this study, divided into two groups: control group (CG) $(n=15$, age: $23.3 \pm 2.1$ years, height: $160.4 \pm 3.4 \mathrm{~cm}$, body mass: $53.5 \pm 2.2 \mathrm{~kg}$ ) and patellofemoral pain syndrome group (PFPSG) ( $n=15$, age: $23.2 \pm 2.3$ years, height: $159.7 \pm 2.8 \mathrm{~cm}$, body mass: $58.7 \pm 3.8 \mathrm{~kg}$ ). For the $\mathrm{CG}$, inclusion criteria were: presence of no more than two PFPS signals in the functional evaluation and absence of pain verified through the Visual Analogue Scale (VAS) during the last month. For the PFPSG, inclusion criteria were: three signals indicating PFPS observed during functional evaluation, pain in at least $3 \mathrm{~cm}$ in VAS during the last month, and report of pain in at least two functional activities (Cowan, Bennell, Crossley, Hodges, \& McConnell, 2002; Cowan, Bennell, Hodges, Crossley, \& McConnell, 2001; Powers, Ward, Fredericson, Guillet, \& Shellock, 2003). Exclusion criteria for both groups were: history of lesion or surgery in the musculoskeletal system, hip, knee, or ankle and individuals with neurological, cardiovascular, or rheumatologic diseases.

All participants had the right leg as the dominant one, and participants in the PFPSG identified their right leg as the one with pain. All procedures of this study were approved by the Ethics Committee in Research of Hospital and Clinics School of Medicine at Ribeirão Preto, University of São Paulo (HCFMRP-USP), Ribeirão Preto, SP, Brazil, n 8089/2007.

\section{Procedures}

The staircase used in this study had three steps (height: $20 \mathrm{~cm}$ for each step) with a force plate (AMTI OR6-7-1000) embedded in the first step (detailed description of the staircase can be found in Saad et al., 2011). Each participant stood in front of the first step and walked up stairs (i.e., three steps) and stop. After that, they turned around and walked down stairs (i.e., three steps) and stopped when they reached the floor. Participants performed this procedure three times starting with the right leg and three times starting with the left leg. The order of the leg used to start the task was completely randomized. Participants should walk up and down stairs following the cadence of $30 \mathrm{steps} / \mathrm{min}$ which were paced to the beats of a metronome.

Force plate registered the forces and moments of force in three directions: anterior-posterior (AP), medial-lateral (ML), and vertical. Data was sampled with a frequency of $100 \mathrm{~Hz}$. Force values were normalized by body weight for each participant.

The transition between braking and propulsive impulses was based on the zero crossing point of the AP component of the GRF (Moraes et al., 2007). As illustrated on Figure 1, after the initial contact with the force plate there was a small oscillation of the AP GRF component around zero, followed by a consistent negative direction of the AP force (i.e., braking phase). After that, force direction changes to positive values, and the instant when this happens (i.e., zero crossing) defines the beginning of the propulsive phase. Braking impulse corresponds to the area under the curve from heel contact on the force plate to zero- 


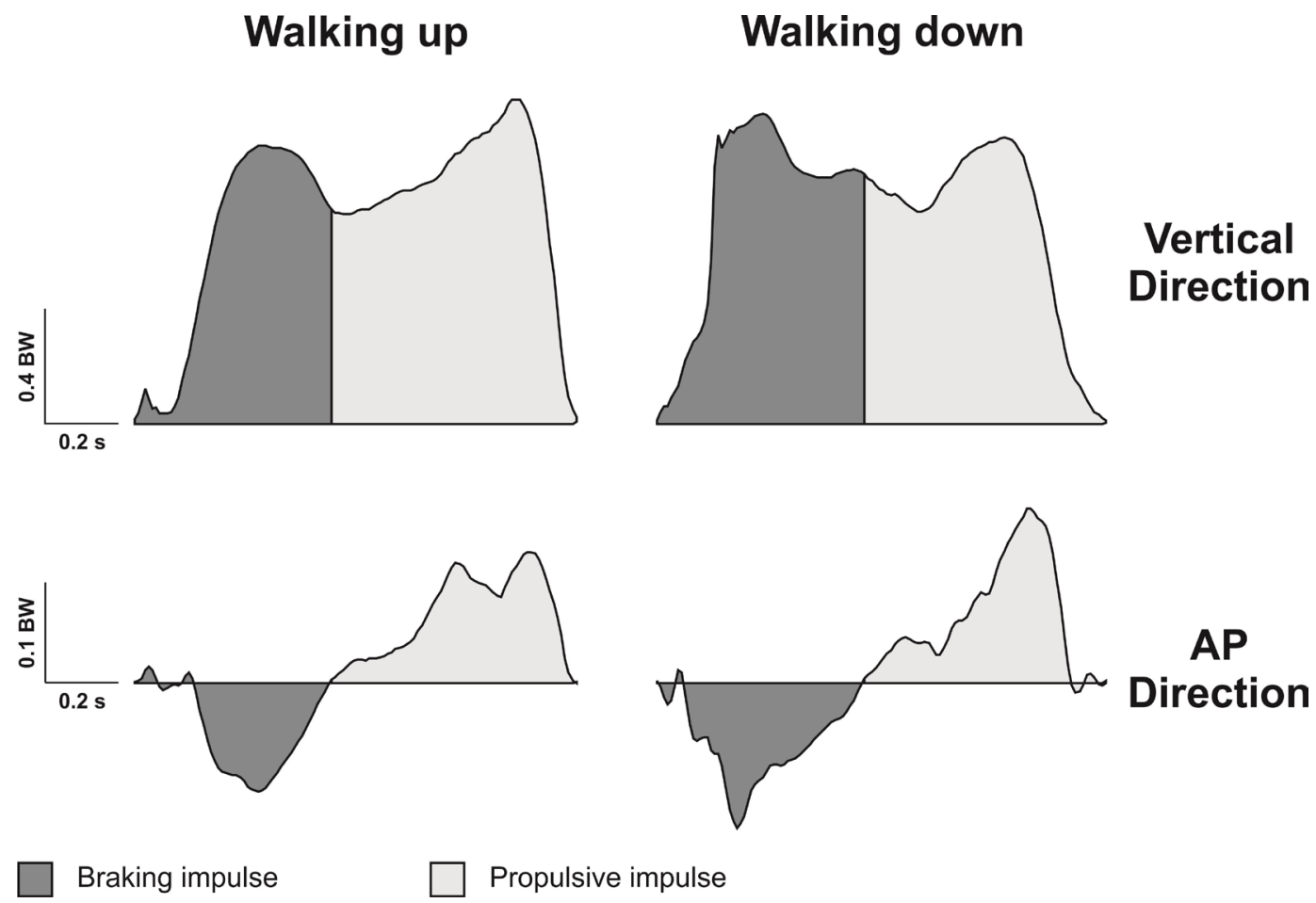

Figure 1. Vertical and anterior-posterior (AP) ground reaction forces for the walking up (left side) and walking down (right side) tasks showing the areas corresponding to braking (dark gray) and propulsive (light gray) impulses for one participant of the present study. BW: body weight.

crossing. Propulsive impulse corresponds to the area under the curve from zero-crossing to toe-off.

\section{Statistical analysis}

Comparisons were made between the dominant and nondominant legs of each group. To analyze and compare the effect of tasks (walk up and down stairs), legs (dominant and non dominant), and groups (control and PFPS), a linear regression model with mixed effects (random and fixed effects) was used (McLean, Sanders, \& Stroup, 1991). Significant levels were defined for $\alpha<.05$, and a confidence interval (CI) of $95 \%$ was calculated. The analysis was performed using the SAS 9.0 software (PROC MIXED function). For the comparisons, we used the posttest by orthogonal contrasts.

Table 1. Mean support, braking, and propulsive duration for control and patellofemoral pain syndrome (PFPS) groups for both walking down and up tasks when using dominant and non-dominant limbs as the leading limb.

\begin{tabular}{|c|c|c|c|c|c|c|}
\hline Tasks & Legs & Control (s) & PFPS (s) & $p$-value & \multicolumn{2}{|c|}{ CI $(95 \%)$} \\
\hline \multicolumn{7}{|c|}{ Support Duration } \\
\hline \multirow[t]{2}{*}{ Walking Down } & Dominant & 1.15 & 1.14 & .79 & -.058 & .076 \\
\hline & Non-dominant & 1.16 & 1.15 & .73 & -.055 & .079 \\
\hline \multirow[t]{2}{*}{ Walking Up } & Dominant & 1.32 & 1.33 & .71 & -.080 & .054 \\
\hline & Non-dominant & 1.37 & 1.35 & .49 & -.043 & .091 \\
\hline \multicolumn{7}{|c|}{ Braking Duration } \\
\hline \multirow[t]{2}{*}{ Walking Down } & Dominant & 0.53 & 0.52 & .31 & -.025 & .080 \\
\hline & Non-dominant & 0.54 & 0.51 & $.05 *$ & .001 & .106 \\
\hline \multirow[t]{2}{*}{ Walking Up } & Dominant & 0.67 & 0.63 & .54 & -.069 & .036 \\
\hline & Non-dominant & 0.61 & 0.65 & .50 & -.071 & .034 \\
\hline \multicolumn{7}{|c|}{ Propulsion Duration } \\
\hline \multirow[t]{2}{*}{ Walking Down } & Dominant & 0.65 & 0.62 & .39 & -.063 & .160 \\
\hline & Non-dominant & 0.63 & 0.64 & .86 & -.122 & .102 \\
\hline \multirow[t]{2}{*}{ Walking Up } & Dominant & 0.65 & 0.70 & .38 & -.162 & .062 \\
\hline & Non-dominant & 0.76 & 0.70 & .09 & -.016 & .207 \\
\hline
\end{tabular}

$* p \leq .05$

CI: Confidence Interval 
Table 2. Mean vertical impulse (braking and propulsive) for control and patellofemoral pain syndrome (PFPS) groups for both walking down and up tasks when using dominant and non-dominant limbs as the leading limb.

\begin{tabular}{|c|c|c|c|c|c|c|}
\hline Tasks & Legs & $\begin{array}{c}\text { Control } \\
\text { (BW.s) }\end{array}$ & $\begin{array}{c}\text { PFPS } \\
\text { (BW.s) }\end{array}$ & $p$-value & \multicolumn{2}{|c|}{ CI $(95 \%)$} \\
\hline \multicolumn{7}{|c|}{ Braking Impulse } \\
\hline \multirow[t]{2}{*}{ Walking Down } & Dominant & 0.46 & 0.48 & .10 & -.036 & .003 \\
\hline & Non-dominant & 0.48 & 0.46 & .10 & -.036 & .003 \\
\hline \multirow[t]{2}{*}{ Walking Up } & Dominant & 0.43 & 0.39 & .39 & -.011 & .028 \\
\hline & Non-dominant & 0.37 & 0.40 & .66 & -.024 & .015 \\
\hline \multicolumn{7}{|c|}{ Propulsive Impulse } \\
\hline \multirow[t]{2}{*}{ Walking Down } & Dominant & 0.45 & 0.43 & .67 & -.049 & .076 \\
\hline & Non-dominant & 0.43 & 0.45 & .41 & -.088 & .037 \\
\hline \multirow[t]{2}{*}{ Walking Up } & Dominant & 0.51 & 0.45 & .06 & -.001 & .124 \\
\hline & Non-dominant & 0.57 & 0.51 & .06 & -.003 & .122 \\
\hline
\end{tabular}

CI: Confidence Interval | BW: body weight

\section{Results}

The comparison between groups for the support and propulsive duration did not reveal any significant difference. For the braking duration, there was a significant difference between control and PFPS groups for the non-dominant limb in the walk down task $(p=.05)$. Braking duration reduced for the PFPS group (Table 1).

The comparison of the braking and propulsive impulses in both vertical and AP directions between the groups is shown in Tables 2 and 3, respectively. No significant differences were observed between groups for any of the comparisons (legs and tasks).

\section{Discussion}

Studies assessing the impulses generated by individuals with PFPS while walking up and down stairs are scarce in the literature. This study demonstrated that individuals with PFPS did not differ from the healthy individuals with respect to the impulses generated while ascending and descending the stairs. However, this result contradicted the hypothesis that PFPS in- dividuals would reduce braking and propulsive impulses when walking down stairs. When walking up stairs, our results agree with the hypothesis that impulse would not change between groups. Remember that these hypotheses were based on the study by Saad et al. (2011). They assessed the peak value of vertical component of the GRF while walking up and down stairs and showed a reduction in both active and passive peaks for individuals with PFPS when walking down stairs. There was no difference between groups when walking up stairs.

PFPS individuals displaced their weight with less intensity onto the affected limb as a way of protecting their limb and avoiding pain when walking down stairs (Saad et al., 2011). Thus, when individuals walked down stairs, neither the task requirement nor their level of pain reported at the time of the examination within a range of mild to moderate-was enough to affect GRF peak (Saad et al., 2011). Moreover, the activity and the level of pain were not important enough to change the GRF peak when walking up stairs.

The fact that individuals with PFPS were able to reduce the peak value of the vertical GRF and, at the same time, maintain impulse generation at the same level as the control individuals

Table 3. Mean anterior-posterior impulse (braking and propulsive) for control and patellofemoral pain syndrome (PFPS) groups for both walking down and up tasks when using dominant and non-dominant limbs as the leading limb.

\begin{tabular}{|c|c|c|c|c|c|c|}
\hline Tasks & Legs & Control (BW.s) & PFPS (BW.s) & $p$-value & \multicolumn{2}{|c|}{ CI $(95 \%)$} \\
\hline \multicolumn{7}{|c|}{ Braking Impulse } \\
\hline \multirow[t]{2}{*}{ Step Down } & Dominant & -0.04 & -0.04 & .20 & -.001 & .006 \\
\hline & Non-dominant & -0.04 & -0.04 & .06 & .000 & .007 \\
\hline \multirow[t]{2}{*}{ Step Up } & Dominant & -0.03 & -0.03 & .13 & -.006 & .001 \\
\hline & Non-dominant & -0.03 & -0.03 & .88 & -.004 & .003 \\
\hline \multicolumn{7}{|c|}{ Propulsive Impulse } \\
\hline \multirow[t]{2}{*}{ Step Down } & Dominant & 0.04 & 0.04 & .93 & -.005 & .005 \\
\hline & Non-dominant & 0.04 & 0.04 & .37 & -.007 & .003 \\
\hline \multirow[t]{2}{*}{ Step Up } & Dominant & 0.03 & 0.03 & .09 & -.009 & .001 \\
\hline & Non-dominant & 0.03 & 0.04 & .22 & -.008 & .002 \\
\hline
\end{tabular}

CI: Confidence Interval | BW: body weight 
do when walking down stairs suggest that they use a protective mechanism to reduce overload on the lower limbs joints. However, they were still able to generate impulse to modify body momentum as much as necessary to perform the task successfully.

This maintenance of impulse, similar to the control group, can be achieved by different mechanisms. One possibility is to increase the duration of the braking and propulsive phases. In this case, the reduction in the peak values would be compensated by applying less force for a longer time. This was not the case because there was no difference for support, braking and propulsive duration between groups (except for the braking duration and the non dominant limb). Another possibility is that individuals slightly increase force production with the same phase duration. This seems to be the most probable mechanism used by the PFPS individuals. In this case, it is possible that participants reduced the peak values to protect the lower limbs from overload, but increased the force levels around these peak values. Therefore, they would be able to compensate for the reduced peak values applying more force distributed over time.

It is important to note that a limitation of this study was that it only included individuals with mild, moderate, or slight pain at the time of the examination. Individuals with more intense pain may behave differently.

\section{Conclusion}

This study demonstrated that patients with PFPS were able to maintain braking and propulsive impulse similar to healthy control individuals when performing a simple functional activity such as walking up and down stairs. Therefore, the activity of ascending and descending the stairs can be recommended as part of the rehabilitation and functional training of individuals with PFPS.

\section{References}

Begg, R.K., Sparrow, W.A., \& Lythgo, N.D. (1998). Time-domain analysis of foot-ground reaction forces in negotiating obstacles. Gait and Posture, 7, 99-109.

Boling, M.C., Padua, D.A., Marshall, S.W., Guskiewicz, K., Pyne, S., \& Beutler, A. (2009). A prospective investigation of biomechanical risk factors for patellofemoral pain syndrome: the Joint Undertaking to Monitor and Prevent ACL Injury (JUMP-ACL) cohort. American Journal of Sports Medicine, 37, 2108-16.

Boling, M.C., Padua, D.A., Marshall, S.W., Guskiewicz, K., Pyne, S., \& Beutler, A. (2010). Gender differences in the incidence and prevalence of patellofemoral pain syndrome. Scandinavian Journal of Medicine \& Science in Sports, 20, 725-30.

Brechter, J.H., Powers, C.M. (2002). Patellofemoral joint stress during stair ascent and descent in persons with and without patellofemoral pain. Gait and Posture, 16, 115-23.

Cowan, S.M., Bennell, K.L., Hodges, P.W., Crossley, K.A., \& McConnell, J. (2001). Delayed onset of electromyographic activity of vastus medialis obliquus relative to vastus lateralis in subjects with patellofemoral pain syndrome. Archives of Physical Medicine and Rehabilitation, 82, 183-9.

Cowan, S.M., Bennell, K.L., Crossley, K.M., Hodges, P.W., \& Mc- connell, J. (2002). Physical therapy alters recruitment of the vasti in patellofemoral pain syndrome. Medicine \& Science in Sports \& Exercise, 34, 1879-85.

Da Cunha, R.A., Costa, L.O., Hespanhol Junior, L.C., Pires, R.S., Kujala, U.M., \& Lopes, A.D. (2013). Translation, cross-cultural adaptation, and clinimetric testing of instruments used to assess patients with patellofemoral pain syndrome in the Brazilian population. Journal of Orthopaedic and Sports Physical Therapy, 43, 332-9.

Davis, I.S., \& Powers, C.M. (2010). Patellofemoral pain syndrome: proximal, distal, and local factors, an international retreat, April 30May 2, 2009, Fells Point, Baltimore, MD. Journal of Orthopaedic and Sports Physical Therapy, 40, A1-16.

Enoka, R.M. (2008). Neuromechanics of human movement. Champaign, IL: Human Kinetics.

McLean, R.A., Sanders, W.L., \& Stroup, W.W. (1991). A unified approach to mixed linear models. American Statistician, 45, 54-64.

Magalhães, E., Fukuda, T.Y., Sacramento, S.N., Forgas, A., Cohen, M., \& Abdalla, R.J. (2010). A comparison of hip strength between sedentary females with and without patellofemoral pain syndrome. Journal of Orthopaedic \& Sports Physical Therapy, 40, 641-637.

Mochida, L.Y., Cesar, G.M., Lobo da Costa, P.H., Santiago, P.R.P. (2009). Estudo dinamométrico da marcha de idosas ultrapassando obstáculos. Revista Brasileira de Educação Física e Esporte, 23, 15-23.

Moraes, R., Allard, F., \& Patla, A.E. (2007). Validating determinants for an alternate foot placement selection algorithm during human locomotion in cluttered terrain. Journal of Neurophysiology, 98, 1928-40.

Nakagawa, T.H., Moriya, E.T., Maciel, C.D., \& Serrão, A.F. (2012). Frontal plane biomechanics in males and females with and without patellofemoral pain. Medicine \& Science in Sports \& Exercise, 44, 1747-55.

Patla, A.E., Robinson, C., Samways, M., \& Armstrong, C.J. (1989). Visual control of step length during overground locomotion: task-specific modulation of locomotor synergy. Journal of Experimental Psychology: Human Perception and Performance, 15, 603-617.

Peterson, C.L., Kautz, S.A., \& Neptune, R.R. (2011). Braking and propulsive impulses increase with speed during accelerated and decelerated walking. Gait \& Posture, 33, 562-567.

Powers, C.M., Ward, S.R., Fredericson, M., Guillet, M., \& Shellock, F.G. (2003). Patellofemoral kinematics during weight-bearing and non-weight-bearing knee extension in persons with lateral subluxation of the patella: a preliminary study. Journal of Orthopaedic and Sports Physical Therapy, 33, 677-85.

Saad, M.C., Felício, L.R., Masullo, C.L., Liporaci, R.F., \& BevilaquaGrossi, D. (2011). Analysis of the center of pressure displacement, ground reaction force and muscular activity during step exercises. Journal of Electromyography \& Kinesiology, 21, 712-718.

Warren, W.H., Young, D.S., \& Lee, D.N. Visual control of step length during running over irregular terrain. Journal of Experimental Psychology: Human Perception and Performance, 12, 259-66.

Zeni Jr, J.A., \& Higginson, J.S. (2009). Differences in gait parameters between healthy subjects and persons with moderate and severe knee osteoarthritis: a result of altered walking speed? Clinical Biomechanics, 24, 372-378.

\section{Authors' note}

Marcelo Camargo Saad, Renato Moraes, and Débora Bevilaqua-Grossi are affiliated with the Graduate Program of Rehabilitation and Functional Performance, University of São Paulo (USP), Ribeirão Preto, São Paulo, Brazil. 
Lilian Ramiro Felicio is affiliated with the Physical Education and Physical Therapy Faculty, Federal University of Uberlândia, Uberlândia, Minas Gerais, Brazil.

\section{Corresponding author}

Marcelo Camargo Saad

Prédio da Fisioterapia e Terapia Ocupacional da Faculdade de Medicina de Ribeirão Preto da Universidade de São Paulo, Avenida Bandeirantes, 3900, Bairro Monte Alegre, 14049-900, Ribeirão Preto/SP, Brazil.

Phone: 55-16-99188 2576

E-mail: marfisiousp@yahoo.com.br

\section{Acknowledgements}

This study received financial support of São Paulo Research Foundation - FAPESP. This study is part of a master's thesis.

Manuscript submitted on November 28, 2013

Manuscript accepted on October 20, 2014

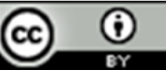

Motriz. The Journal of Physical Education. UNESP. Rio Claro, SP, Brazil - eISSN: 1980-6574 - under a license Creative Commons - Version 3.0 